\title{
Paideusis
}

\section{Education and the Market Model}

\section{John McMurtry}

Volume 5, Number 1, 1991

URI: https://id.erudit.org/iderudit/1073355ar

DOI: https://doi.org/10.7202/1073355ar

See table of contents

Publisher(s)

Canadian Philosophy of Education Society

ISSN

0838-4517 (print)

1916-0348 (digital)

Explore this journal

Cite this article

McMurtry, J. (1991). Education and the Market Model. Paideusis, 5(1), 36-44.

https://doi.org/10.7202/1073355ar

(C) John McMurtry, 1991

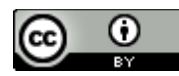

This document is protected by copyright law. Use of the services of Erudit (including reproduction) is subject to its terms and conditions, which can be viewed online.

https://apropos.erudit.org/en/users/policy-on-use/
This article is disseminated and preserved by Érudit.

Érudit is a non-profit inter-university consortium of the Université de Montréal, Université Laval, and the Université du Québec à Montréal. Its mission is to promote and disseminate research.

https://www.erudit.org/en/ 


\title{
Education and the Market Model ${ }^{1}$
}

\section{John McMurtry, University of Guelph}

\begin{abstract}
Our government is creating an alternative paradigm-enabling individuals to purchase service from providers who are independent of government, but which are obliged to be more responsive to the customers thus enabled. (Robert Jackson, Minister of Higher Education, Great Britain.)
\end{abstract}

Education has always been subject to external pressures that seek to subordinate its practices and goals to vested interests of some kind, whether of slave-holding oligarchies, theocratic states, political parties or merely prevailing dogmas of collective belief. The history of the development of social intelligence is largely a history of this conflict between the claims of education and inquiry, on the one hand, and the demands of ruling interests and ideologies, on the other. Today is no different. And as in the past, those charged with society's educational function today have been disinclined on the whole to challenge the ascendant social power which seeks to reduce learning and reflection to its organ and instrument. Yet this reduction, this subordination to an external system of rule with very different and even opposed goals to education is already very far advanced. To this point, it has been supported rather than resisted by established educational leaderships themselves.

As we know, governments across the English-speaking world have been imposing sustained and extensive cutbacks on higher education expenditures since the late 1970s. Numerous academic departments have been closed down in Britain and the United States, per-student funding has plummeted almost $30 \%$ in real terms in Canada, financial support and grants for non-military research have widely and variously declined across the academic disciplines, and so on. ${ }^{2}$ The accumulating facts form a pattern of continuous funding reduction too evident to labour here. In general, university administrators have responded to this program of cumulative cutbacks by searching for ways to justify education that will motivate governments, and increasingly corporations, to provide more adequate financing. For some years now, without much critical notice, this justification of higher education has taken the form of a clearly non-educational rationale. To be precise, it has taken the form of justifying higher education as necessary to compete economically in the international marketplace. There are many variations on this now universal theme--" to keep us at the forefront of the world economy." "to provide the investment in human capital our society requires to adapt to the rapidly changing global economy," "to sustain the acquisition of knowledge as a principal source of comparative advantage," and so on.

Business leaderships have meanwhile energetically backed businesssupported governments in pressing the universities to "adapt to the new reality," of competing to survive in business and market terms. The Chairman of Bell-Northern Research Limited, for example, has publicly counselled universities that " $85 \%$ of university research isn't worth reading ... it's curiosity oriented." His model is Stanford University in California "'because it's an industrial park, not a science park." 3 U.S. Xerox Chairman, David Kearns, in a policy initiative supported by News and World Report in November 1989, has argued that: "Public education is a $\$ 150$ billion a year business ... Business will 
have to set the new agenda ... a complete restructure [sic] driven by competition and market discipline, unfamiliar ground for educators." 4 The Canadian Manufacturers Association has echoed these demands: "Our system of higher education [must function] as an engine of development ... Universities must be encouraged to shed low-yield, costly baggage from the past." 5

To these pressures to conform to the market model of education, there has been little resistant response by educational administrators at any level. An instructive example here is Canada's largest province, Ontario, which has been near the forefront of higher-education development in North America since the 1960s. As far back as 1984, University of Toronto's far-seeing president accommodatingly headlined his President's Page in the University's Alumnus Magazine "The Campus as Corporation."6 The former principal of Queen's University, Dr. Ronald Watts, developed this theme further in a discussion paper circulated prior to the 1988 Ontario Council of University Faculty Associations Forum. "Post-secondary education," he argued, "should be seen as an investment in the nation's adaptiveness and international competitiveness, not a binder on the public purse." Dr. Tom Brzustowski, former Vice-President Academic and Provost at the University of Waterloo, and now Ontario's Deputy Minister of Colleges and Universities, put the matter more categorically: "I contend that the one global object of education in Ontario must necessarily be a greater capability of the people of Ontario to create wealth ... [to] export products in which our knowledge and skills provide the value added ... to develop new services which we can offer in trade on the world market."7

One could go on with the evidence of this overall pattern of educational administrators at the highest levels pressed by corporate executives at the highest levels and threatened with ever further cuts in real income from governments, taking up the demand that public education be primarily devoted to serving business interests in intemational economic competition. What was traditionally education's by-product function is now proclaimed as its ultimate goal.

It is important to remind ourselves just how far the basic research and teaching process has already been subordinated to corporate control. Academic awards and grants are now so universally trade-named by multinational corporations that few remain which are not dependent for their survival on business or business foundation sponsorship. Textbook production and distribution in public educational institutions is now almost entirely under the control of large corporations, with over two-thirds of the school text market in North America controlled by just eight multinationals. ${ }^{8}$ Academic teachers, under Chapter 15 of the new Canada-United States Free Trade Agreement, are now conceptualized by the national governments of the United States and Canada as "business persons" who function as "providers of goods and services" subject to the requirements of free trade across borders. Even the language of educational purpose has undergone a sea-shift of transformation into business terminology and the going discourse of the corporate culture: "resource units" for what used to be subject disciplines and their professors; educational "consumers" for what used to be students and learners; "uniform standards" for what used to be the search for quality, depth, originality; "program packages" for what used to be curriculum; "products" for what used to be graduates; "buying" ideas for what used to be understanding truth. It is difficult to avoid the conclusion that the 
educational process has been so pervasively subordinated to the aims and practices of business that its agents can no longer comprehend their vocation in any other terms.

Educators since Plato have traditionally resisted the reduction of education to the demands of appetite and social conditioning. But what has been clearly lacking from even those more reflective educators today who intuit that the integrity of education is being undermined by its increasing submission to the rule of the market is any clear understanding of the oppositions in principle between them. The problem is thus posed. Without these bearings of analytic understanding, educators are quite unable to comprehend, let alone resist, the totalizing assimilation of the goals and methods of education to those of commodity production and sale.

The following anatomy of the defining differences between the principles of the market and of education provides the logical framework we require. The differences which it identifies demonstrate that the aims and processes of education and the market are not only distinct, but contradictory. Once we have understood this deep-structural opposition of their requirements, we are better able to appreciate that the reduction of the one to the other poses a problem at the foundations not only of education, but of human culture itself.

\section{The Contradictions in Principle Between Education and the Market Model:}

\section{(1) Opposing Goals:}

The overriding goal of corporate agents in the marketplace is to maximize private money profits.

\author{
The overriding goal of educational \\ agents in schools, colleges, and \\ universities is to advance and dis- \\ seminate shared knowledge.
}

The opposition here has two principal dimensions: (i) the nature of the good that is sought, and (ii) the logic of its acquisition.

(i) Money is a socially recognized unit of demand for externally produced commodities. Knowledge is the opposite. It is not a homogeneous unit, and not a demand for externally produced commodities, but a variable ability of internal comprehension. The two kinds of good are opposed as material to mental possession, uniform artifact to individuated capacity, and demand on the world to competence of oneself.

(ii) Private profit is acquired by a structure of acquisition that excludes others from its appropriation. The greater the amount of its accumulation for self, the greater the inaccessibility of others to any use or control of any unit of its possession. Knowledge, on the other hand, is acquired by a structure of appropriation that does not exclude others from its acquisition, but on the contrary is maximized the more its accumulation is shared by others and the more others have access to every step of its development. Knowledge which is not conveyed to others is wasted or "dead", and all knowledge-accumulation begins with the unpaid gifts of others and is dependent for its increase on the "free exchange of ideas." 


\section{(2) Opposing Motivations:}

The determining motivation of the market is to satisfy the wants of whoever has the money to purchase the goods that are wanted.
The determining motivation of education is to develop the understanding that is sought

The opposition here, again, has two main dimensions: (i) the motivation to be fulfilled and (ii) the beneficiaries of this fulfilment.

(i) To "satisfy the wants of customers" is the universally proclaimed goal of all who sell goods in the market. Profits achieved from doing this, in turn, are enjoyed or invested by their owners in whatever way they want as the entailment of their ownership remaining private. Want-satisfaction is, in short, the overriding motivation of the market for both buyers and sellers, and the primary justification of the market as an organizing principle of social exchange.

The development of understanding, in contrast, is never assured by and is often opposed to the satisfaction of the wants which the market serves. What you want to buy or to consume can and usually does block what is required of you to develop understanding, as the continuous diversion of students from their education to commercial television, rock records or mall wandering demonstrates. Development of understanding is necessarily growth of cognitive capacity, whereas satisfaction of consumer wants involves neither, and typically impedes both.

(ii) The market by definition can only satisfy the motivations of those who have the money to buy the products it sells. The place of education, on the other hand, remains a place of education only insofar as it educates those whose motivation is to learn, independent of the money demand they exercise in their learning. As the ancient archetypes of the penniless scholar and the Croesusrich buyer reveal, the motivations of education and the market are opposite and their fulfilment is conferred on opposite types.

\section{(3) Opposing Methods:}

The method of the market is to buy or to sell the goods it has to offer to anyone for whatever price one can get.

\author{
The method of education is never \\ to buy to sell the good it has \\ to offer but to require of all \\ who would have it that they fulfil \\ its requirement for themselves.
}

Everything that is to be had on the market is gotten by the money paid for it. Nothing that is leamed in education is gotten by the money paid for it. A money fortune cannot ensure an iota of education, though it can provide the external conditions for an education to be pursued, or neglected. In education, the learner must always earn it autonomously, because an education is always by the processes of one's own mind. In the market, its goods never need to be earned autonomously, and are in principle never the product of one's own work. That is why an education that can be bought on the market is a fraud, and why the purchase of another's performance to get it elsewhere is an expulsionable cheat. The method of achievement education requires rules out the method of the market as its most essential violation.

This opposite method of appropriation of the goods of the market and of 
education leads to opposite consequences of use. Every good that is produced and purchased on the market is eventually consumed or worn out, whereas the more and longer an education is put to work, the better and more durable it grows. While all commodities produced for the market are depreciated in value by their use, an education can never be consumed, and never ceases to appreciate in value by its use. In short, the methods of the market and education are opposite both in their logic of acquisition and in their nature of value transformation.

(4) Opposing Standards of Excellence:

The measures of excellence in the market are: (i) how well a productline is made to sell; and (ii) how problem-free the product is and remains for its buyer.
The measures of excellence are (i) how disinterested and impartial its representations are; and (ii) how deep and broad the problems it poses are to the one who has it.

It is well-known that the highest aim of market communications is to impel its recipients into wanting to buy a product. This is achieved by one-sided sales pitches, and processes of operant conditioning which only work if they are not understood. On the other hand, an education must rule out one-sided presentation, appetitive impulsion, and manipulative conditioning by the very nature of its process. This is why the worst one could say about an advertising campaign is that it makes rigorous demands on people's reason, and, conversely, the worst one could say about an educational program is that it gives biased appeals to unconscious desires.

(ii) The best product on the market, as we know, is the one which is the most "problem-free" for its purchaser--delivered "readymade" for "instant easy use," "guaranteed replacement" if it does not work, and "repaired costfree" whenever it needs maintenance attention.

The best education, on the other hand, is the opposite on all standards of evaluation. It cannot be produced or delivered by another at all, is never ready made nor instant, and cannot be guaranteed replacement or service cost-free if it is not working. The higher the standards it has, the less it can be immediate in yield, the more work it demands of its owner, and the more its failures must be overcome by its possessor's own work.

An education can never be "problem-free" by its nature, and poses ever deeper and wider problems the higher the level of excellence it achieves.

At the bottom of these contradictions of standard is an ultimate contradiction between logics of achievement: development of one's own capacities for autonomous use versus development of external conveniences for others to depend upon. The better the education, the more its bearers become independent to think and do on their own. The better the market, the more its agents depend on others to provide their thinking and doing for them.

This fundamental contradiction in standards of attainment leads, in turn, to opposite standards of freedom. Freedom in the market is the enjoyment of whatever one is able to buy from others with no questions asked, and profit from whatever one is able to sell to others with no requirement to answer to anyone else. Freedom in the place of education, on the other hand, is precisely the freedom to question, and to seek answers, whether it offends people's acquired 
routines of enjoyment and profit or not. What is the best policy for buying a product--to assert the customer's claim as "always right"--is the worst possible policy for a learner. What is the best policy for selling a product--to offend no-one and no vested interest--may be the worst possible policy for an educator. The principles of freedom here are contradictory, and become the more so the more each is realized.

\section{Counterarguments}

I. One counterargument to the systematic contradiction we have found between the principles of the market and of education is that, in fact, formal education has been the training ground for business and labour positions since at least the late nineteenth century, and this subordination of education to economic demands is an unavoidable requirement of any contemporary technologically advanced social order. With increasing global competition in recent years, this imperative of educating for the marketplace has simply become more demanding--requiring more of education than in the past to keep abreast of rapid international changes in efficiency of production. The change here does not consist in a takeover of education by external corporate control, but rather in updated requirements of what has long determined modern formal education, society's economic system.

Reply: This counterargument does not deny what is asserted, that the principles of education and of the market are contradictory. Rather, it implicitly accepts this contradiction under a covering generalization about the necessity of the economic determination of public education in contemporary industrialized society. This is another, very broad issue of metaphysical dimensions which cannot be adequately analysed here. It does, however, raise the stakes of our problem. If society's education system is ineluctably determined by economic requirements, and these economic requirements are the requirements of established market-capitalism, then it follows that we face the prospect of an inevitable transformation of our educational process into an organ of the capitalist market. Since, as we have seen, the logic of the market and of education are opposed, this economic determination of education must entail ex hypothesi the systematic negation of educational goals and standards. With education thus subserved to a universalized corporate circuit of producing consumer goods for profitable sale, what can remain of mental life beyond or outside of this circuit? Because a society's educational process bears "the best that humanity has thought and said" to its next generations, its absorption into the oppositely disposed process of commodity manufacture and sale, must leave society in a very real sense without its historically achieved capacity to think. It becomes a kind of mass creature, a collective system of gratifying desires for profit and consumption with no movement beyond itself towards understanding and consciousness as a human end-in-itself.

The instrumental reason of market gain may indeed have a basic place in our lives in efficiently ensuring the consumer goods we want or need, but to reduce all of instituted social culture to moments of its further increase makes an organizational tool of humanity its master, and inverts human life into a mere means of its means. What the counterargument above highlights is the full parameters of our predicament. The economic determinism it affirms entails that the subjugation of education to market principles occurs as necessity, and 
cannot but succumb to its negation. This is not a denial of the argument, but an hyperbolization of the problem to which it points.

II. A second counterargument adopts the opposite tack. It claims that the contradictions the argument finds between the principles of education and of the market cannot be wholly true because, in fact, capitalist corporation managers increasingly recruit for employees who can think autonomously, critically, and dialogically in the very way that traditional educational values require. Moreover, this counterargument can continue, commodities produced for and sold in the market--for example, novels, learned texts and scientific documentaries--are often used effectively in places committed to authentic educational values, and indeed sometimes lead the way in introducing new modes and directions of teaching and research which institutions of formal education might otherwise be inclined to resist. On these two accounts, then, the counterargument concludes, the principles of education and of the market cannot be systematically contradictory, but must be to some extent complementary or co-incident in aim.

Reply: Most employees in the market are not, in truth, selected for their autonomous, critical, or dialogical thinking. Those employees who are thought to be so selected, a small management minority, are not permitted to be autonomous, critical and dialogical in any way that might challenge the firm's right to maximize its profits, that might expose its practices of unfairness or pollution, that might question the social need for its products, that might recognize a competitor's wares as of better value, that might criticize the firm's or a superior's policies, or that might independently publish internal research findings. All of these, we know, are permitted in an institution of higher education as standard entitlements of academic freedom. The autonomous, critical and dialogical thinking that is recruited for in a private corporation, in contrast, is only permitted if it is believed to contribute to the firm's goal of profitable marketing of its products. Such thinking, clearly, is not genuinely autonomous, critical, or dialogical. It is extrinsically motivated, compliant with command, and pre-emptive of any alternative not judged to advance the employer's own interests. Only that self-direction, critical assessment, or altemative viewpoint is valued which is thought to promote the employer's chances of private, commercial advantage.

The second part of the counterargument presupposes that independent institutions of education exist from which profit-seeking enterprises can draw their expertise (e.g., scientists for scientific texts), and to which they can market their educative products (e.g., literary classics to academic courses). The question arises, however, whether without independent academies in which scientists are trained to strict impartiality and students are required to think deeper than television plots, the market would field either scientifically reliable texts or cognitively challenging books. Given that economies or international scale now regulate market production, and production for mass consumption appeals to the lowest common denominators of human intelligence to maximize sales, it is not clear where a profitable market for strict impartiality, creative difficulty, or philosophical analysis would come without independent educational institutions to provide the demand and the expertise for their continuance as viable forms of human life.

It is true that as an autonomous sphere of independent purposes and prac- 
tices, the educational institution can be complemented and assisted by the efficient operations of a capitalist market, but only so far as it remains independent and govemed by its own different principles. There can be no vital interaction of polar fields of human enterprise if one pole's field is absorbed by the other: in particular if the rationally disinterested and critical capacity of our being is absorbed by the materially acquisitive and desire-gratifying side--in this direction lies disaster. Totalization of the profit-and-consumption pattern is not only incompatible with the survival of education, but, as we are coming to know more evidently still, it eventually endangers the biosphere and planet itself. Recognition that market imperatives cannot be universalized, but must be limited by the independent claims of other forms of life, is a lesson which only what is able to critically reflect on the market, that is, an autonomous educational process, is in the institutional position to effectively ensure.

\section{Summary}

The defining principles of education and of the marketplace are systematically contradictory in: (1) their goals, (2) their motivations, (3) their methods, and (4) their standards of excellence. It follows, therefore, that to understand the one in terms of the principles of the other, as has increasingly occurred in the application of the market model to the public educational process, is absurd. It follows, more momentously for practice, that the demand that one operate in terms of the other's opposed requirements, as has been increasingly demanded of the educational process, is a root-and-branch assault on education as such. If it is permitted to continue, and demand becomes compulsion, it must end in the destruction of education itself, though doubtless the market will continue to advertise some of its wares as "educational." We are facing the increasing reduction of the historically hard-won social institution of education to a commodity for private purchase and sale.

Education is being made to become its opposite by what might be called "the totalitarian moment" of the capitalist marketplace in its period of greatest triumph and global pervasion, a moment that is ironically celebrated as a "victory of freedom" for all. What is required to keep the commodity market in its proper place and to prevent the inversion of education under its demands, is first of all the recognition that they are systematically opposed and not, as we have so far mutely accepted, related as end to means. Despite Orwell's gloomy prophecies, we are not able to hold contradictories in our mind as equivalent so long as their contradiction is known.

\section{References}

R.F. Amove (ed.). Philanthropy and Cultural Imperialism: The Foundations at Home and Abroad. Bloomington: Indiana University Press, 1982.

John Griffith, Universities and the State: The Next Steps. London: Council for Academic Freedom and Democracy, 1989.

John Kenneth Galbraith. "Research and the Military." Globe and Mail Report on Business, April 13, 1990.

John McMurtry. "The History of Inquiry and Social Reproduction: Educating for Critical Thought." Interchange, 19(1), (September) 1988, 31-45. 
Leonard Minsky and David Noble, "Corporate Takeover on Campus." The Nation, (October) 1989.

Herbert I. Schiller, Culture Inc.: The Corporate Takeover of Public Expression. Oxford: Oxford University Press, 1990.

\section{Notes}

${ }^{1}$ This paper was originally prepared for presentation to the Canadian Association of Foundations of Education, Victoria, B.C., June 1990. I am grateful to Paul Axelrod, Bill Graham, John Griffith, Israel Helperin, and Howard Woodhouse for helpful comments at various stages of the paper's construction, and to participants of the Conference for their lively responses.

2."Columbia University has dispensed with its geography and linguistic programs. Johns Hopkins cut back on spending for arts and sciences, and Washington University in St. Louis dismantled its well-regarded sociology department. ... A recent survey by the Association of American Universities indicated that at least 60 per cent of A.A.U. institutions are 'consolidating, eliminating, or reducing academic departments' (Minsky and Noble, 1989, 496)." John Kenneth Galbraith, in a paper delivered at the University of Guelph, Canada, in October 1989, calculated that the research and development budget of the U.S. Department of Defence ( $\$ 40$ billion per annum) and of military-related Department of Energy and National Aeronautics and Space Administration budgets (\$5 billion per annum) approximately triple all other U.S. research and development expenditures of $\$ 15$ billion per annum (Galbraith, 1990, B2). In Britain, "some University grants were reduced to less than 50\% ... Humanities departments have been particularly hard-hit--Philosophy lost between $30 \%$ and $40 \%$ of its positions. At least twelve British universities now have no philosophy departments at all." (Graham, 1990, 2)

${ }^{3}$ Paul Axelrod, "Services of Captivity? Business-University Relations in the Twentieth Century," in William A.W. Nielson and Chad Gaffield (eds.), Universities in Crisis (Montreal: Institute for Research on Public Policy, 1986), 57.

${ }^{4}$ David T. Kearns and Denis P. Doyle, Winning the Brain Race: A Bold Plan to Make our Schools Competitive (San Francisco, California: ICS Press Institute for Contemporary Studies, 1988), 42.

5William Graham, "From the President," Ontario Confederation of University of Faculty Associations Bulletin, 6(15), 1989, 3 and 6(22), 1990.

6David Strangway, "The Campus as Corporation," University of Toronto Alumnus Magazine, (January/February) 1984, 19.

${ }^{7}$ William Graham, op. cit.

${ }^{8}$ Roland Lorimer and Joan McNulty, Mass Communications in Canada (Toronto: McClelland and Stewart, 1987), 232. 